\title{
An Approach to a Theory of Subject Headings
}

$\mathrm{T}$ HE END of the war has brought increased demands on libraries. Problems of building a peaceful world are numerous and complex. Not only do we have to deal with much new material, but whole groups of our population-trade unions, women, Negroes, national minorities-that have come to positions of greater national importance, present new problems and points of view. The number of fields which do not have adequate bibliographical tools of their own will probably increase rather than diminish. Keeping subject catalogs up to date and in line with contemporary needs will be much more important than in the past.

But our subject catalogs have not been adequate even for past needs. Reference librarians express continuing dissatisfaction with the results of current practices; administrators worry about their cost and usefulness; library school teachers have spoken of the difficulty of teaching subject heading work; evidence of reaction by the public is inevitably diffuse and spotty, but all that is available suggests dissatisfaction and unmet needs.

Is there a pattern, a common element, in all the varying specific problems of subject heading work? If we turn to the literature - perhaps 250 titles in English in the last half-century-we find lists of headings, discussions of specific headings or criticisms of particular practices, and advice as to where to look for new headings, but almost nothing by way of underlying principles, of theoretical generalizations. Such principles as have been formulated-those in Miss Mann's textbook, for example-seldom have more of a rational basis than the writer's personal experience of the fact that most libraries do it that way. There is little that would help answer such questions as: What elements determine the formulation of a new heading? Or, How can one evaluate the subject catalogs of a particular library?

The reasons for this lack of theory are clear. It is only within the past decade or so that scientific methods have been applied to any branch of library procedure. The pattern of internal development in the larger libraries as well as various social forces have tended to make cataloging appear merely as a complex mechanical procedure, when actually it is an important educational function.

A theory is a statement of principles underlying a whole field, a generalizing of facts and experience for the purpose of guiding further work in the field. With reference to our immediate problem the principal uses of theory would be to simplify the teaching of subject heading techniques; to provide a rational basis for handling questions of level of specificity, subordination, and inversion; to aid in the development of new headings; and to assist catalogers in handling difficult titles. Probably it would incidentally provide a sounder basis for spreading knowledge of how to use catalogs and indexes and furnish criteria for evaluation of lists of headings and of particular catalogs.

Recent empirical studies such as those of 
Knapp, ${ }^{1}$ Quigley, ${ }^{2}$ Swank, ${ }^{3}$ and Van Hoesen, ${ }^{4}$ will provide material for testing and elaborating a theory, but they cannot alone produce one. Ultimately, the piling up of discrete empirical studies without the sorting, criticizing, and tying together of their results, which is the function of theory, would lead to further confusion.

The function of a subject heading is to enable groups of readers to find from the whole body of literature, material which will help satisfy their specific needs. Attempts to define subject headings in terms of "books"-commercially published, monographic works-comprise even a majority of the physical units processed. What, then, is the unit to which a subject heading relates? What is a subject?

A particular piece of literature is nearly always written for a specific group of people. Its writing and publishing is, in fact, a social process in which a number of individuals or organizations participate. But the boundaries between different activities are neither fixed nor watertight. As a particular field develops, the people concerned with it frequently come to have need for materials that were written for quite different groups; thus the workers in a certain branch of economics may find indispensable, papers or books that were written originally for mathematicians. Or a title may be useful, less for its formal subject matter than for the point of view expressed or generalization made. (An article on the economic aspects of the book trade, ${ }^{5}$ for example, would be of considerable use to

1 Knapp, P. B. "Subject Catalog in the College Library." Library Quarterly.14:108-18, 214-28, April, July 1944 .

${ }^{2}$ Quigley, H. "Investigation of the Possible Relationship of Interbranch Loan to Cataloging." Library

Quarterly I4:333-38, October I 944 .
8 Swank, R. C. "Organization of Library Materials for Research in English Literature." Library Quar. terly I $5: 49-74$, January I 945 .

1 Van Hoesen, H. B.; "Perspectives in Cataloging, with Some Applications." Library Quarterly 14:100-07, April 1944:

'Schneider, Isidor, "Monopoly in Book Publishing." New Masses, Mar. 5, 1946, p. 23-24. those concerned with the position and responsibilities of the creative writer in contemporary society.) Moreover, new activities, new emphases on old ones, do not develop at random. They grow out of definite changes-economic, political, technological-in society. This is true even for the development of new specialties in scientific fields; while such developments are influenced by the past history and the internal relations of particular sciences, more general social forces are the deciding elements in determining lines of work, what is emphasized or neglected, in even the most "abstract" sciences. The extreme complexity of modern society must not blind us to the fact that there are always patterns, definite-and often predictable - trends, in the development of intellectual activities and, hence, of the demand for printed materials.

Subjects, then, are definable in terms of the needs of people working in particular fields, and these are always growing, overlapping. The literature of physics includes all the material that may be useful to physicists, whatever its original source and purpose. Let us call the units to which subject headings relate, sectors of literature. A sector is defined as a part of the whole field of literature which is useful to a continuing, socially determined group of people with common interests and activities. For the sake of convenience we shall designate the latter as interest groups.

The principal value of this concept is that it focuses attention on the people who use books, on the actual uses to which printed materials are put, rather than on the books and journal articles themselves. Attempts to define "subjects" without reference to users of libraries are not relevant to cataloging work.

Just what bearing does this idea have on subject heading work? How, as a practical 
matter, are sectors to be defined and subject headings formulated? Through familiarity with current activities in particular scientific, technical, political, historical, or other fields. Because people are constantly working with them, ideas, concepts, processes, always have names, and the names used by people who are working in a field will usually be the best guide to correct and permanent subject headings. In a few very specialized and rapidly advancing scientific fields-possibly vitamin research, for example - this may mean daily activity in the field. But in most cases a familiarity with the literature and the way in which it is being used-the activities, trends, relations with other fields-will be sufficient.

\section{An Example}

Consider cartels, for example. A cartel is a specific form of monopoly, defined as an agreement between the heads of two or more firms to control production, allocate markets, and/or fix prices. The term has been standardized for at least twenty years and several groups are concerned with the topic; one recent bibliography ${ }^{6}$ covers 120 pages. Both the Library of Congress and the Readers' Guide enter material on cartels (along with that on several other forms of monopoly) under the heading "Trusts, Industrial." But an industrial trust is a different kind of monopoly, one that is now illegal in the United States and so largely of historical interest. Lumping them all together under the same heading is as useful as would be putting the literature on apples and pears under the same term because they are botanically related.

A somewhat more complex type of case is illustrated by anti-Semitism. There is a considerable amount of material on the problems of anti-Semitism and ways of com-

${ }^{6}$ Conover, H. F. Cartels, Combines and Trusts: a Selected List of References. Washington, Library of Congress, 1944. batting it. It is essential that the whole be easily available. To enter it under a much more general heading such as "JewsPolitical and Social Conditions" is comparable to burying all the material on geology under the heading "Science."

It may be objected that the use of specific headings in controversial fields would involve judgments of the material which a cataloger is not competent to make. But judgments must be made in any case; they are as inescapable as breathing. Continued entry of material such as that mentioned under broader or antiquated headings (thereby implying that the needs of people who use correct terms are not significant) represents as much an intellectual-and in many cases a political_-judgment as would use of the correct terms. There are rational, objectively valid ways of dealing with the unpleasant facts of the world.

Returning to specific practical problems, what difference might this approach make in cataloging work? The usual process of formulating a new subject heading is something like this: Here is a book on a new subject; can we find a suitable term in an index or encyclopedia? (And there is rarely any attempt to evaluate or criticize the practice, say, of a periodical index.) If not, what word or phrase can be used as a heading? Ordinarily new subject headings are formed by head or senior catalogers who have little if any contact with people who use libraries and who are only occasionally specialists in a particular field. With rare exceptions, the problem of publicizing a new heading is ignored.

In the light of the above discussion, the procedure should probably be somewhat as follows: Here is a new body of literature. For whom is it written? To what groups, for what purposes, will it be useful? What are the main trends or centers of interest of these groups? Will there be much or little 
material, and what forms will it take? To what extent will people who need this material be aided by older titles now under other headings? Will cross-references suffice or should additional subject entries be made for some of the older titles? Workable answers can be gotten for all these questions by anyone familiar with current activities in the field. The correct subject heading will usually emerge in the process of answering these questions. So will the answer to the question, Who among our own clientele should be told about new subject headings?

\section{Specialized Knowledge}

Recognition of the importance of close and continuing knowledge of activities in specific fields should bring several changes in the organization of cataloging work. For one thing, it makes clear the significance of special lists of subject headings. The idea that special libraries need specialized subject headings more than large general libraries, is hardly valid. Only rarely do special libraries have bodies of material not contained in university and research libraries. By and large, the same people use both types of institutions. The better special lists have value precisely because they have been compiled by librarians who have closer contact with the workers in a particular field and who are more thoroughly acquainted with its literature than catalogers in a general library. There appears to be no good reason why new headings developed by competent special librarians should not immediately be adopted by the larger general libraries.

In the universities there is a promising field for experimentation in the use of certain faculty members and research workers on a part-time basis either for consultation or for routine subject heading and classification work. This would create a number of administrative and training problems, but there is no reason for believing they would be impossible of solution. An immediately practical step in the larger libraries would be the fuller utilization for cataloging work of reference department and subject-matter department workers, as suggested by Lund. The Subject Cataloging Division of the Library of Congress has already made some progress in the recruiting of specialists for cataloging work in scientific fields. Moreover, fuller development of a body of theory should lead to a more extensive standardization of subject headings and, hence, to greater possibilities for centralized and cooperative cataloging. While there is no single, easy solution for the problem of getting into catalog departments workers familiar enough with various special fields to catalog adequately materials in those fields, combinations of several administrative steps would make the problem much less overwhelming than it may seem at first sight. It is quite true that people who have both a working knowledge of one or more fields and some facility in subject heading work will not be available for forty dollars or even sixty dollars per week, but this only takes us to the more general problem-into which we can hardly go here-of the need for sharp increases in all library salaries. It is worth noting, however, that all available experience indicates that the output of a cataloger who knows a particular field is so much greater than that of a general cataloger working in the same field, that differences in salaries would be more than covered.

\section{Technical Questions}

Apart from administrative problems, two or three technical points may be noted.

7 Lund, J. J. "Cataloging Process in the University Library: a Proposal for Reorganization." College and Research Libraries 3:21 2-18, June 1942. 
One is the question of technical versus popular terms. The textbook proposition that university and technical libraries should use technical terms as subject headings while public libraries should use popular ones, is a vulgarization of the actual situation. People are constantly moving from one educational level to another. Even a clubwoman who is writing a brief paper on infantile paralysis will learn in the process that the correct name for that disease is poliomyelitis; incidentally, she will probably also learn that these two terms are not completely synonymous, that the former is occasionally used to cover birth injuries. In general, the correct-and hence most nearly permanent-terms will be those used by people who are working in a particular field. The indexes to both Biological $A b$ stracts and Experiment Station Record freely use a mixture of "popular" and technical terms, apparently preferring the former whenever they are specific and stable enough.

\section{Inversion}

Then there is the question of inversion. The argument that it is desirable to bring together in the catalog several aspects of the same topic ("Insurance, Fire;" "Insurance, Life," etc. $)^{8}$ involves a confusion of purpose. It is not a function of the alphabetical subject catalog to bring together material in logically related fields. In all dual aspect headings the question is, which form -inverted or direct-is the correct name for the sector to which it relates? The answer is neither a matter of subjective personal opinion nor of abstract logic, but of the purposes for which material on a topic is written and used. Even a casual acquaintance with the literature on unemployment insurance, for example, will show

8 Mann, M. Introduction to Cataloging and the Classification of Books. Chicago, American Library Association, 1943, 2nd ed., p. 144. that the emphasis is almost entirely on the economic and social effects of unemployment and the place of insurance among other devices for protecting or cushioning workers against it, with only very incidental attention given to the technical aspects of insurance as a device for distributing risks or losses. With the possible exception of certain chemicals, it is difficult to think of any case where inversion is justified by anything more than the desire to tie new topics to old established headings, thus saving work-actually only postponing it-for catalogers.

The question as to whether certain topics should be subordinated to larger topics or given headings of their own will, again, be decided properly in terms of actual use of the material. Readers' Guide, for example, subordinates material on dismissal pay to the larger topic "Wages" and enters material on small business firms in the form "Business-Small Business." But dismissal pay is a specific problem in labor relations; there are several groups of people concerned with it. The problems of small business firms are numerous and complex enough that at least two Congressional committees have been concerned largely with them. Material on both these topics will be made most easily available in catalogs and indexes by giving them headings of their own. On the other hand, the material on the educational or health activities of trade unions will best be subordinated to "Trade Unions" because the fact that the activities reported are being done by trade unions is what gives them significance for various groups of readers.

\section{Need for Further Study}

Space does not permit the consideration here of the work relating to subject head-

(Continued on page 255) 
Schools limits its membership to faculties of accredited library schools. This in effect means that those schools which might conceivably benefit most by association are excluded from the advantages of an effective means for the interchange of professional library teaching ideas. This association of all library schools would be similar to the American Library Association for general librarianship ; it would welcome all interested in library educational problems.

With detailed knowledge of present teaching techniques in use in all library schools and with an association admitting the entire professional library teaching personnel, we would have the lever and the wheel necessary for an examination of what teaching in the field of librarianship should be. At this point a third step toward our

\section{A Theory of Subject Headings}

\section{(Continued from page 248)}

ings of Bliss $^{9}$ or Kelley ${ }^{10}$ or of practical rules proposed by Van Hoesen. ${ }^{11}$ But several problems needing further investigation should be noted. At first glance, one might expect that an increased number of headings would mean a much greater number of cross references, but there is some reason for thinking that fuller use of correct and up-to-date headings would mean fewer see and see also references; the relative scarcity of both in such a detailed and specialized index as that of Psychological Abstracts is interesting in this connection. The relation between the theory suggested above and the classified catalog needs discussion. My own experience, as well as that of Helen Starr, ${ }^{12}$ is

9 Bliss. H. E. Organization of Knowledge in Libraries and the Subject Approach to Books. New York City, Wilson, I 939

10 Kelley. G. O. Classification of Books: an Inquiry into Its Usefulness to the Reader. New York City, Wilson, I 937

${ }_{11}$ Van Hoesen, op. cit.

12 Starr, H. K. "Subject Headings in a Changing World." Library Journal 59:2'05, Mar. I, I 934. professional philosophy may be taken by inviting practicing librarians and the users of their libraries to contribute to the understanding of the type of library personnel which should be produced.

These three steps are in themselves an enormous order, and the goal lies still further. This goal of librarianship is well known. Librarianship aims to mate readers and ideas found in printed and nonprinted materials in any way that will be fruitful. What is not well known is that it is much easier to see where you want to go than to provide and utilize the means for getting there. The crucial problems in a philosophy of librarianship are not scientific or philosophical, but engineering problems concerned with time, money, and personnel with ingenuity for fitting means to ends.

that the use of more specific headings reduces the average number of subject entries per title (actually, since a cataloger who is also a subject matter specialist can often omit less essential added or title entries, savings are even greater); whether this would hold true for all fields is a problem to be investigated. Catalogers who are also subject specialists would undoubtedly discover legitimate needs which our catalogs do not now meet $;^{13}$ on the other hand, they could probably withdraw large numbers of cards relating to fields where adequate bibliographies are available. The approach to subject headings suggested here implies changes in the organization of cataloging work and in library school curricula. But these problems are better left for future discussion.

\footnotetext{
${ }^{13} \mathrm{Cf}$. McMurtrie, D. C. "Locating the Printed Source Material for United States History." Mississippi Valley Historical Review 3I:369-406, December I 944 .
} 